\title{
Daytime spawning of Porites rus on the coral reefs of Chumbe Island in Zanzibar, Western Indian Ocean (WIO)
}

Received: 15 December 2010/Accepted: 31 January 2011/Published online: 16 February 2011

(C) Springer-Verlag 2011

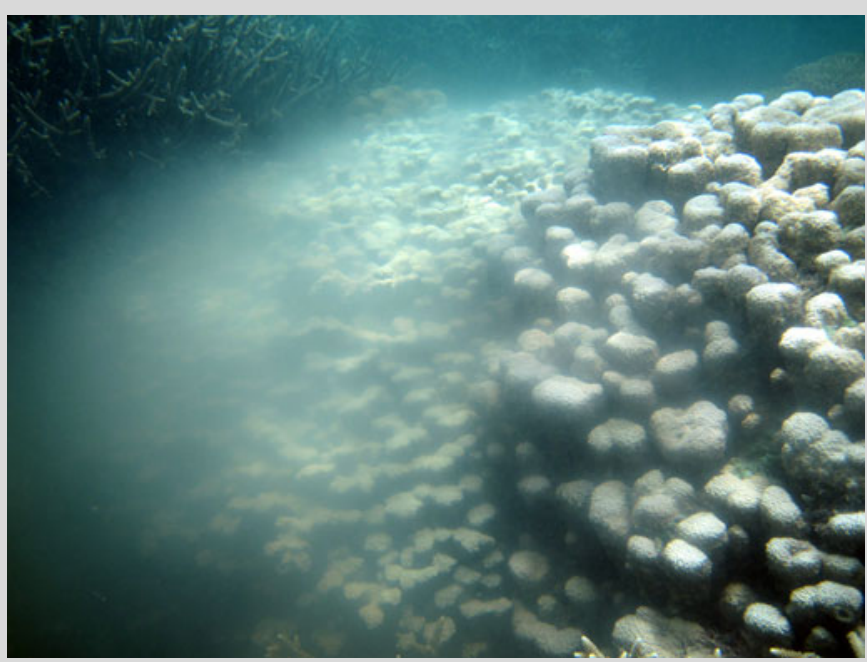

Fig. 1 Sperm ejecting from a colony of Porites rus
The majority of scleractinian corals spawn during nighttime (Harrison and Wallace 1990). Daytime spawning is rare, and mostly occurs in early morning or late afternoon with only several species reported to spawn during midday (e.g., Pavona sp. and Fungia danai; Plathong et al. 2006; Mangubhai et al. 2007). The most common combination of sexuality and mode of reproduction currently known for scleractinian corals is hermaphroditic spawning (63\%), while gonochoric brooding is the least common combination (7\%) (Baird et al. 2009). However, in the genus Porites, the relative abundance of gonochoric brooders is almost five times higher than in the majority of other scleractinia, involving up to $33 \%$ of currently known species (Baird et al. 2009).

During a survey of the Chumbe Island Coral Park $\left(06^{\circ} 16.7^{\prime} \mathrm{S}, 039^{\circ} 10.4^{\prime} \mathrm{E}\right)$, several colonies of $P$. rus, measuring $1.5-5 \mathrm{~m}$ in diameter, were observed spawning in midday on the islands western reef flats (Fig. 1). Thirteen (13) colonies were observed spawning during low tide, at depths of 1-3 m, between 11 and 12 a.m on November 26, 2010, 5 days after the full moon. Big clouds of sperm were released to the water column in bursts that lasted over $20 \mathrm{~min}$. In the western Pacific, P. rus has been identified as a gonochoric spawner (Penland et al. 2004); however, no

reports on $P$. rus sexuality or mode of reproduction in the WIO currently exist in the literature. Here, we present the first documentation of $P$. rus spawning at this part of the WIO and the first midday spawning observation for this species. Furthermore, since egg release was not observed in any of the spawning colonies (as might be expected), our findings suggest $P$. rus in the WIO to be a gonochoric brooder in contrast to its western Pacific conspecific.

\section{References}

Baird AH, Guest JR, Willis BL (2009) Systematic and biogeographical patterns in the reproductive biology of scleractinian corals. Annu Rev Ecol Syst 40:551-571

Harrison PL, Wallace CC (1990) Reproduction, dispersal and recruitment of scleractinian corals. In: Dubinsky Z (ed) Ecosystems of the world: coral reefs. Elsevier, Amsterdam, pp 133-207

Mangubhai S, Harris A, Graham NAJ (2007) Synchronous daytime spawning of the solitary coral Fungia danai (Fungiidae) in the Chagos Archipelago, central Indian Ocean. Coral Reefs 26:15

Penland L, Kloulechad J, Idip D, van Woesik R (2004) Coral spawning in the western Pacific Ocean is related to solar insolation: evidence of multiple spawning events in Palau. Coral Reefs 23:133-140

Plathong S, Chanmethakul T, Suwonno V, Buaphet P, Baird AH, Chen CA (2006) Daytime gamete release from the reef-building coral, Pavona sp., in the Gulf of Thailand. Coral Reefs 25:72

O. Bronstein $(\bowtie) \cdot$ Y. Loya

Department of Zoology, George S. Wise Faculty of Life Sciences, Tel Aviv University, 69978 Tel Aviv, Israel e-mail: omribronstein@gmail.com

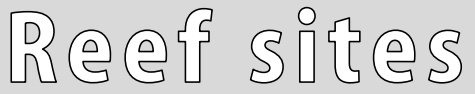

Coral Reefs (2011) 30:441

DOI $10.1007 / \mathrm{s} 00338-011-0733-7$ 